\title{
Willingness to Use a Public Bicycle System: An Example in Nanjing City
}

\author{
Peiyu Feng and Wenquan Li \\ Southeast University, China
}

\begin{abstract}
The purpose of this paper is to examine the influence factors on willingness to use a public bicycle system and to analyze the impact of each. Ordered Logit and Probit models were used to analyze the change in user willingness after improvements were made. Data were collected from a random survey conducted in September and October 2014 in Nanjing, China. The findings of this research indicate seven factors that most influence willingness to use a public bicycle system, including socioeconomic factors and journey restrictions. Socioeconomic factors (gender, employment, and car ownership) have more impact on user willingness than journey restrictions. In addition, socioeconomic and station facility considerations have the greatest impact on increasing the probability of users being "very willing" to use a public bicyucle system.
\end{abstract}

Keywords: Public bicycle system, influencial factors, users' willingness to choose the public bicycle system

\section{Introduction}

Today, China is faced with severe traffic congestion, environmental pollution, and other urban problems. Therefore, Chinese government decision-makers strongly advocate for the development of multimodal "green" transportation systems. Transit priority allows public transportation to be a more attractive option for commuters and has been proposed as a national strategy to reduce people's increasing reliance on automobiles (State Council 2012). Public bicycles, which have significant advantages for short journeys and easily connect to other public transportation systems, also can be used as a complementary and alternative form of public transit system to solve the "last mile" problem in China's public transportation model.

Between 2010 and 2014, about 25 new public bicycle systems were implemented annually in China. Based on available data, until February 2014, these systems operated approximately 425,000 public bicycles and 16,105 public bicycle stations and had 4,362,879 bike-sharing members in China. Like China, many cities in Europe and North America have developed public bicycle systems, which have become increasingly popular. 
To date, studies of public bicycle systems have been focused on policies, layout, and deployment. Demaio (2009) shows a history of bike-sharing, starting with the first generation "white bike" in 1965. Shaheen et al. (2010) summarized the benefits of bike sharing as providing flexible mobility, reducing traffic congestion, reducing emissions, providing individual financial savings, and supporting multimodal transport connections. Rainer-Harbach et al. (2013) state that a general variable neighborhood search (VNS) with an embedded variable neighborhood descent (VND) is necessary to redistribute bicycles in a public bicycle system. The research of Raviv et al. (2012) presents an inventory model suited for the management of such bicycle systems.

Other researchers have examined factors associated with public bicycle system usage. Bachand-Marleau et al. (2012) found that convenience and avoidance of bike theft and maintenance are key factors in the use of the BIXI bike sharing programs in Montreal. Convenience emerged as the primary importance factor for public bicycle system use in studies published in recent years. Another factor directly associated with convenience is the distance between user homes and the closest docking station. However, these recent studies did not focus on willingness to use a public bicycle system. Research on this topic can help with the forecasting and scheduling of user demands and is important for researching the optimization of public bicycle docking stations and public bicycle system management.

A review of the literature (Hensher et al. 2010; dell'Olio et al. 2010) shows that Ordered Logit and Probit models can be used as discrete choice models that more efficiently characterize different transport systems qualities. These often are carried out with ordered scales of data, as this is an essential characteristic in determining the dependent variable of Ordered Logit and Probit models.

The goal of this paper is to examine the influential variables and their relevance to willingness to use a public bicycle system based on discrete choice models (Ordered Logit and Probit models) using data from Nanjing, China, where public bicycle system use (Figure 1) is on the rise and innovative public bicycle system planning has taken place in recent years.
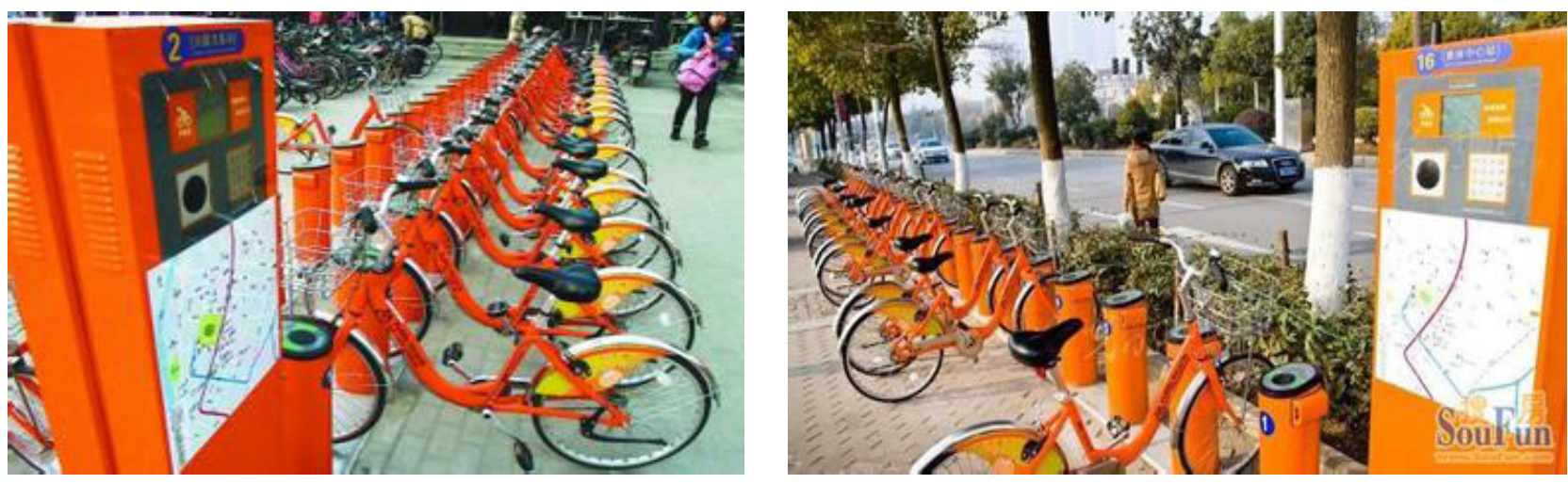

FIGURE 1. Public bicycle system in Nanjing 


\section{Methodology}

Discrete choice models are based on random utility, which provides information on an individual's behavior when faced with a choice and subjected to certain socioeconomic characteristics and journey constraints (Ortuzar and Willumsen 2011). Dell'Olio et al. (2010) used discrete choice models to research the overall quality of a bus transit system. These models also were used to study user satisfaction with a transport service (Givoni and Rietveld 2007). User willingness to use the public bicycle system examined in this paper looks at how users perceive the quality of the service being provided by the public bicycle based on whether they score themselves as "very willing," "willing," "unwilling," or "very unwilling" to use the public bicycle system. This choice-making is the evaluating process according to a range of possibilities on an ordered scale and also meets with the discrete choice modeling process.

Hensher et al. (2010) and dell'Olio et al. (2010) showed that an Ordered Logit and Progit model can be used as a discrete choice model; it has been used to arrange the qualifications and levels in the definition and research of user choice willingness for the public bicycle system in this paper.

The Ordered Logit and Probit model is defined as (McKelvey and Zavoina 1975):

$$
\mathrm{y}=a+\sum_{k=1}^{k} \beta_{k} x_{k}+\varepsilon
$$

where $y$ represents the dependent variable and J represents the type of dependent variable, expressed as $1,2, \ldots$, J. Therefore, $\mathrm{y}=1, \mathrm{y}=2, \ldots \ldots \mathrm{y}=\mathrm{J} .{ }^{x_{k}}$ represents independent variables, $\mathrm{K}$ represents the sum of all variables, ${ }^{\beta}{ }_{k}$ represents the coefficient of ${ }^{x_{k}}$, and $\mathrm{k}=1,2, \ldots \ldots, \mathrm{K} . \varepsilon$ represents the random term.

The Ordered Logit and Probit model has a regression format in which the dependent and unobservable variable $y^{*}$ is a linear function of a group of independent variables $x_{i}$ and random term $\varepsilon$.

$$
\mathrm{y}^{*}=a+\sum_{k=1}^{k} \beta_{k} x_{k}+\varepsilon
$$

The discretization of the variable $y$ is done using following equations:

$$
\begin{aligned}
& \mathrm{y}=0 \text {, if } \mu_{-1}<y_{i}^{*} \leq \mu_{0} \\
& \mathrm{y}=1 \text {, if } \mu_{0}<y_{i}^{*} \leq \mu_{1} \\
& \mathrm{y}=2 \text {, if } \mu_{1}<y_{i}^{*} \leq \mu_{2} \\
& \cdots \\
& \mathrm{y}=\mathrm{J}, \text { if } \mu_{J-1}<y_{i}^{*} \leq \mu_{J}
\end{aligned}
$$


where $\beta_{k}$ and $\mu$ are the parameters needed to be estimated by the model. $\beta_{k}$ represents the weights of each independent variable and the importance of each in the dependent variable. The parameters $\mu$ are the limits of defining the dependent variable $y$. The random term $\varepsilon$ represents the error.

According to the relationship between $y$ and $\mathrm{y}^{*}$, the cumulative probability $\mathrm{P}(\mathrm{y} \leq \mathrm{j})$ $(j=1,2 \ldots, J-1)$ is expressed as:

$$
\begin{aligned}
\mathrm{P}(\mathrm{y} \leq \mathrm{j})=\mathrm{P}\left(\mathrm{y}^{*} \leq \mu_{j}\right) & =P\left(a+\sum_{k=1}^{k} \beta_{k} x_{k}+\varepsilon \leq \mu_{j}\right) \\
& =\mathrm{P}\left[\varepsilon \leq \mu_{j}-\left(a+\sum_{k=1}^{k} \beta_{k} x_{k}\right)\right] \\
& =\mathrm{F}\left[\mu_{j}-\left(a+\sum_{k=1}^{k} \beta_{k} x_{k}\right)\right] \\
& =\mathrm{F}\left(\beta_{o j}-\sum_{k=1}^{k} \beta_{k} x_{k}\right)
\end{aligned}
$$

Where $\mathrm{F}$ expresses the cumulative distribution function of $\varepsilon .{ }^{\varepsilon}$ is subordinated to logistic distribution, and the logistic function is:

$$
\begin{aligned}
& \mathrm{g}(x)=\frac{1}{1+e^{-x}}, F\left(\beta_{0 j}-\sum_{k=1}^{k} \beta_{k} x_{k}\right)=\frac{1}{1+\mathrm{e}^{-\left(\beta_{0 j}-\sum_{k=1}^{k} \beta_{k} x_{k}\right)}} \\
& \mathrm{P}(y \leq j)=\frac{1}{1+e^{-\left(\beta_{0 j}-\sum_{k=1}^{k} \beta_{k} x_{k}\right)}}=\frac{e^{\left(\beta_{0 j}-\sum_{k=1}^{k} \beta_{k} x_{k}\right)}}{1+e^{\left(\beta_{0 j}-\sum_{k=1}^{k} \beta_{k} x_{k}\right)}}
\end{aligned}
$$

where P represents the cumulative probability, $y$ represents the dependent variable, and $\mathrm{J}$ represents the type of dependent variable, expressed as $1,2, \ldots, \mathrm{J}$. Therefore, $\mathrm{y}=1$, $\mathrm{y}=2, \ldots \ldots . \mathrm{y}=\mathrm{J} .{ }^{x_{k}}$ represents independent variables, $\mathrm{K}$ represents the sum of all variables, $\beta_{k}$ represents the coefficient of $x_{k}, \mathrm{k}=1,2, \ldots . . ., \mathrm{K} . \mathrm{K}$ represents the sum of all variables, and $\beta_{0 j}$ represents an intercept.

According to the change in a variable, the Ordered Logit and Probit model has been calibrated to quantify the change in choice willingness when improvements are made to the influencial variables. The partial effects represent the probability of a specific result for $y$. The value of these effects could be either negative or positive depending on whether they represent a decrease or increase in probability of choosing each alternative for $y$. The partial effects are represented by $\varepsilon_{\mathrm{j}}\left(x_{i}\right)$ : 


$$
\delta_{\mathrm{j}}\left(x_{i}\right)=\frac{\partial P(y=j)}{\partial x_{i}}=\left[f\left(\mu_{j-1}-\beta^{\prime} x_{i}\right)-f\left(\mu_{j}-\beta^{\prime} x_{i}\right)\right] \beta
$$

The accumulated value of the partial effects of all the variables is also of interest:

$$
\frac{\partial P(y=j)}{\partial x_{i}} \sum_{m=0}^{j}\left[f\left(\mu_{j-1}-\beta^{\prime} x_{i}\right)-f\left(\mu_{j}-\beta^{\prime} x_{i}\right)\right] \beta=-f\left(\mu_{m}-\beta^{\prime} x_{i}\right) \beta
$$

\section{Reseach Context}

\section{Survey Analysis}

The methodology presented in this paper was put into practice in Nanjing, Jiangsu

Province, China. The city of Nanjing is the second-largest commercial center in the East China region after Shanghai and the transportation hub of eastern China. Nanjing also boasts an efficient network of public transportation, which consists mainly of bus, taxi, and metro systems. To help solve the inherent problems of public transportation, a public bicycle system was introduced into Nanjing in five districts. Currently, 560 public bicycle sites have been set up, which now have more than 16,000 bicycles.

The analysis in this study combines data from a questionnaire administered to commuters in the Metro stations of the Jiangning, Pukou, Hexi, and Gulou districts. The survey respondents, who were taking the subway, were recruited using a random approach, and the surveys were conducted from September to October 2014. A total of 800 survey forms were distributed, and 608 valid forms were returned. Forms were considered invalid if they were not properly completed or if many important questions were skipped. This survey's efficiency was approximately $76 \%$.

The analysis of the data collected (Figure 2) shows that more males (52.6\%) responded with valid surveys than females (47.4\%). People who were ages 16-29 were the most prevalent responders (43.6\%), followed by those ages 30-39 and 40-49, who accounted for $26.3 \%$ and $16.7 \%$, respectively. The highest frequency of use of public bicycles was on work days (58.9\%), followed by once a week (24.7\%) and occasional use (4.1\%). Regarding employment, people working as staff were shown to be the most prevalent respondents (50.1\%), followed by the other categories (28.3\%). People reporting that they cycled to transfer between other modes of public transport accounted for $59.8 \%$ of respondents; the next most prevalent purpose of travel was traveling to work, followed by entertainment. 

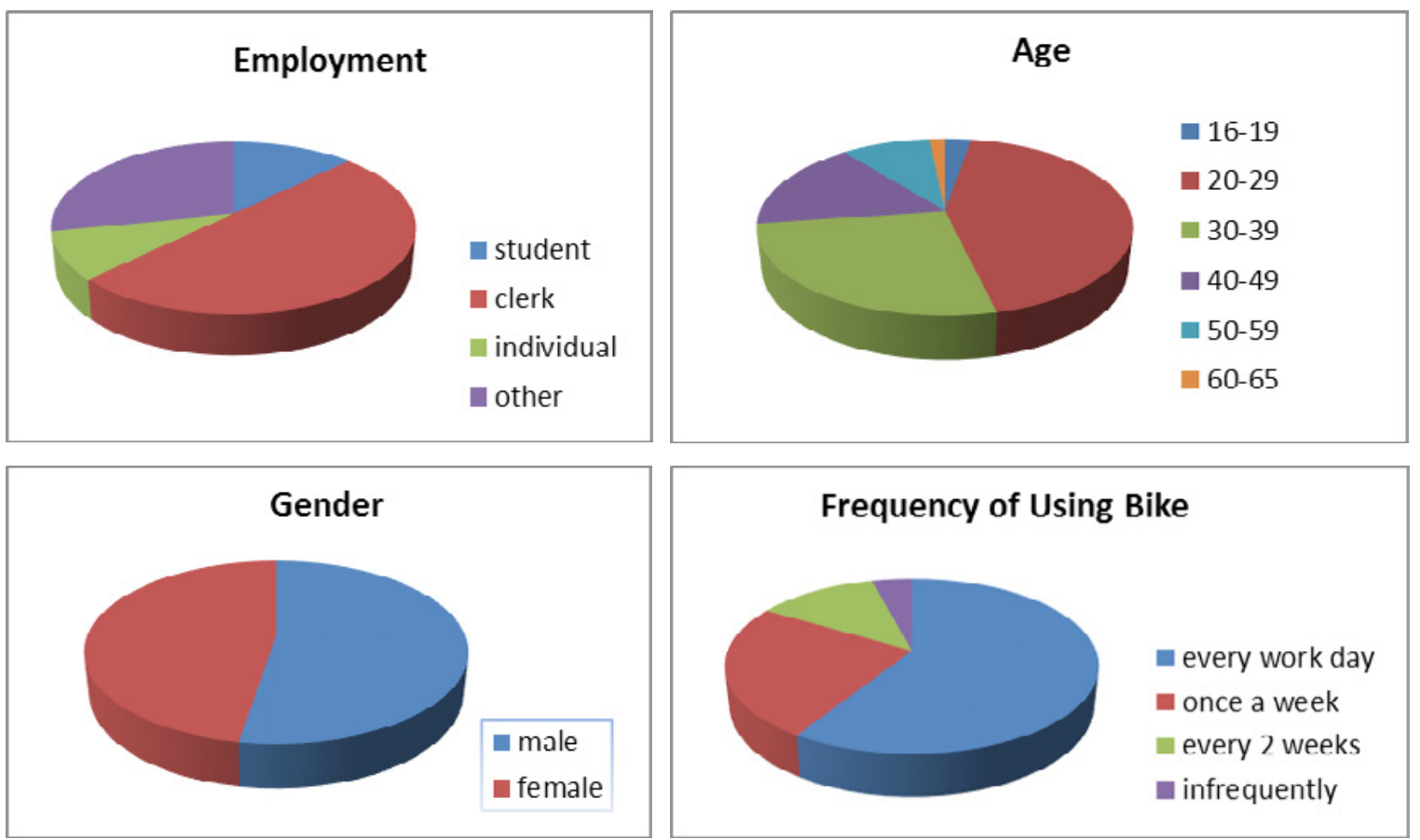

FIGURE 2. Proportions of valid sample of personal and usage characteristics

\section{Analysis of Willingness to Use a Public Bicycle System \\ Preparation}

After the initial analysis of the collected data, the next step was to analyze the willingness to use the public bicycle system by using the Ordered Logit and Probit model to define the dependent variable and independent variables. As described previously, dependent variable y represents the following options: 1 = "very willing," 2 = "willing," 3 ="unwilling," or 4 ="very unwilling." "Very willing" indicates that users would choose to use a public bike whatever the case. "Willing" expresses a preference for sometimes choosing to use a public bike. "Unwilling" indicates that users would not give priority to using a public bicycle, but in some cases may choose it. "Very unwilling" means that users would not use a public bicycle whatever the case.

Research by Ortuzar and Willumsen (2011) found that the use of the Ordered Logit and Probit model allowed interactions to be introduced which may, in many cases, explain user perceptions that might originate in socioeconomic factors or journey restrictions. In this paper, independent variables related to willingness to use a public bicycle system also include socioeconomic factors and journey restrictions. Socioeconomic factors included gender, age, employment, trip purpose, car ownership, and the frequency of public bicycle usage. Journey restrictions included load time at flat peak, load time at peak, length of time of bicycle use, rationality of public bicycle docking station location, and station facility level. Definitions for each variable are provided in Table 1. 
TABLE 1.

Independent Variable

Definitions

\begin{tabular}{|l|l|}
\hline \multicolumn{1}{|c|}{ Independent Variable } & \multicolumn{1}{c|}{ Definition } \\
\hline Gender & User gender \\
\hline Age & User age (divided into 16-29, 30-39, 40-49, above 49) \\
\hline Employment & Classified as students, staff, individual, or other \\
\hline Trip purpose & Classified as work, entertainment, or transfer \\
\hline Car ownership & Owning or not owning a private car \\
\hline $\begin{array}{l}\text { Frequency of public bicycle } \\
\text { usage }\end{array}$ & $\begin{array}{l}\text { Classified as every work day, once a week, once every two } \\
\text { weeks, and infrequently }\end{array}$ \\
\hline Load time at flat peak time & $\begin{array}{l}\text { Length of time user needs to load bicycle, except at peak } \\
\text { time, every day }\end{array}$ \\
\hline Load time at peak time & $\begin{array}{l}\text { Length of time user needs to load bicycle at 7:00-9:00am } \\
\text { or 5:00-7:00 pm every day }\end{array}$ \\
\hline Length of time of bicycle use & Length of time of bicycle usage \\
\hline $\begin{array}{l}\text { Rationality of public bicycle } \\
\text { docking station location }\end{array}$ & $\begin{array}{l}\text { Whether public bicycle docking station is convenient to } \\
\text { user from home }\end{array}$ \\
\hline Station facility level & $\begin{array}{l}\text { Whether sufficient bicycles and bicycle parking spaces } \\
\text { available }\end{array}$ \\
\hline
\end{tabular}

Gender, car ownership, station facility level, and rationality of public bicycle docking station location are two-dimensional variables: males are represented by 1 , and females by 0 ; a good station facility level is represented by 1 , and a poor station facility level by 0 ; owning a private car is represented by 1 , and not owning a private car by 0 ; and a rational public bicycle station location is represented by 1 , and an unreasonable location is represented by 0 .

Age, employment, trip purpose, and the frequency of using public bicycles are categorical variables. Wang and Guo (2001) showed that the approach for coping with categorical variables is to create a dummy variable. In this paper, there are four categories for age: 16-29 is used as the reference category, and 30-39 (age1), 40-49 (age2), and more than 49 (age3) are the dummy variables. When a user's age is 16-29, age $1=$ age 2 age $3=0$; when a user's age is $30-39$, then age $1=1$; otherwise, age $1=0$. For employment, staff is used as the reference category, and student, individual, and other are used as dummy variables. When the user is categorized as staff, job1 (student) $=$ job2 (individual) $=$ job3 (others) $=0$. When the user is categorized as a student, job1 $=1$; otherwise job1 $=0$. To describe the frequency of using public bicycles, every work day is used as the reference category, and $\mathrm{fr} 1, \mathrm{fr} 2$ and $\mathrm{fr} 3$ are the dummy variables; when the frequency of using public bicycles is every work day, fr1 (once a week) $=\mathrm{fr} 2$ ( $\mathrm{a}$ half month at a time) $=\mathrm{fr} 3$ (infrequently) $=0$. To categorize travel purposes, transfer is used as the reference category, and work and entertainment are the dummy variables; when the purpose is categorized as transfer, aim1 (go to work) = aim2 (entertainment) $=0$. Values and meanings for these are shown in Table 2. 
TABLE 2. Measuring Dummy Variables

\begin{tabular}{|l|l|l|}
\hline Virtual Variable & \multicolumn{1}{|c|}{ Meaning } & \multicolumn{1}{c|}{ Values } \\
\hline age1 & age 30-39 & if yes, age1=1; else age1=0 \\
\hline age2 & age 40-49 & if yes, age2=1; else age2=0 \\
\hline age3 & age more than 49 & if yes, age3=1; else age3=0 \\
\hline job1 & student & if yes, job1=1; else job1=0 \\
\hline job2 & individual worker & if yes, job2=1; else job2=0 \\
\hline job3 & other & if yes, job3=1; else job3=0 \\
\hline fr1 & once a week & if yes, fr1=1; else fr1=0 \\
\hline fr2 & once every two weeks & if yes, fr2=1; else fr2=0 \\
\hline fr3 & infrequently & if yes, fr3=1; else fr3=0 \\
\hline aim1 & go to work & if yes, aim1=1; else aim1=0 \\
\hline aim2 & entertainment & if yes, aim2=1; else aim2=0 \\
\hline
\end{tabular}

With regard to the multi-class variables described above, in this paper, independent variables include gender, car ownership, load time at flat peak time, load time at peak time, length of time of bicycle use, rationality of public bicycle docking station location, station facility level, age1, age2, age3, fr1, fr2, fr3, job1, job2, job3, aim1, and aim2. Statistical analysis system (SAS) programming was used to analyze the data.

\section{Procedure}

First, the correlation between willingness to use the public bicycle system and all independent variables was analyzed with the Ordered Logit and Probit model. As the research of Liu et al. (2008) showed that Wald testing could test the coefficient significance of the Ordered Logit and Probit model, Wald testing also was used. Wald $\chi^{2}>3.841$ or $P<0.05$ of the coefficient of variables were found to be related to the dependent variables and were retained. SAS could output the value of Wald $\chi^{2}$ and $P$. Then, variables that did not meet the Wald $\chi^{2}>3.841$ or $\mathrm{P}<0.05$ were deleted until the results of this method contained only variables that were associated significantly with willingness to use the public bicycle system.

Then, the relationship between influencial independent variables and willingness to use the public bicycle system was analyzed. According to the change in an independent variable, the Ordered Logit and Probit model was calibrated to quantify the change in choice willingness when improvements were made to the influential variables. The percentage increase (positive sign) or decrease (negative sign) in the probability of each scale as a result of an improvement in the value of each independent variable was interpreted by the partial effects.

According to the Ordered Logit and Probit model and the rule of Wald testing, the results of data analysis are shown in Table 3. 
TABLE 3.

Results of Data Analysis Using

Ordered Logit and Probit

Model and Wald Testing

\begin{tabular}{|c|c|c|c|c|}
\hline & Variables & Coefficient & Wald $\chi^{2}$ & $P$ values \\
\hline & intercept 1 & 8.8359 & 33.9627 & 0.0001 \\
\hline & intercept 2 & 16.8977 & 57.6328 & 0.0001 \\
\hline & intercept 3 & 23.6258 & 65.8213 & 0.0001 \\
\hline & Itap & $-0.3561^{*}$ & 9.9965 & 0.0001 \\
\hline & ut & $-0.1393^{*}$ & 8.9617 & 0.0012 \\
\hline \multirow[t]{2}{*}{$\begin{array}{l}\text { Rationality of public bicycle } \\
\text { docking station location }\end{array}$} & $\begin{array}{c}\text { yes } \\
\text { (reference category) }\end{array}$ & & & \\
\hline & no & $-0.0838^{*}$ & 6.8911 & 0.0111 \\
\hline \multirow[t]{2}{*}{ Station facility level } & good & $0.9677^{*}$ & 3.9613 & 0.0388 \\
\hline & $\begin{array}{c}\text { no good } \\
\text { (reference category) }\end{array}$ & & & \\
\hline \multirow[t]{2}{*}{ Gender } & female & $2.7344^{*}$ & 9.8727 & 0.0001 \\
\hline & $\begin{array}{c}\text { male } \\
\text { (reference category) }\end{array}$ & & & \\
\hline \multirow[t]{4}{*}{ Employment } & $\begin{array}{c}\text { staff } \\
\text { (reference category) }\end{array}$ & & & \\
\hline & job1 & 1.6321 & 1.1785 & 0.0993 \\
\hline & job2 & -0.8974 & 0.1764 & 0.6353 \\
\hline & job3 & -0.0731 & 0.0059 & 0.7132 \\
\hline \multirow[t]{2}{*}{ Car ownership } & $\begin{array}{c}\text { yes } \\
\text { (reference category) }\end{array}$ & & & \\
\hline & no & $0.9783^{*}$ & 4.6758 & 0.0255 \\
\hline $\begin{array}{l}\text { Proportional odds } \\
\text { assumption }\end{array}$ & & $P=0.6749, \chi^{2}=31.1327$ & & \\
\hline Model $\chi^{2}$ statistics & & $P=0.0001, \chi^{2}=450.449$ & & \\
\hline Aic, sc & & $\mathrm{AIC}=215.233, \mathrm{SC}=260.613$ & & \\
\hline $\begin{array}{l}\text { Somers'd, gamma, } \\
\text { Tau-a,c }\end{array}$ & & $0.680,0.682,0.519,0.842$ & & \\
\hline
\end{tabular}

* Significant at 0.05 confidence level

** Significant at 0.1 confidence level

\section{Findings and Discussion}

As the results of this research show, the seven most important factors that influence willingness to use the public bicycle system were identified and included load time at peak (Itap), length of time using bike (ut), rationality of public bicycle docking station location (ra), station facility level (el), gender (female), car ownership (not owning a private car), and employment (job1). These factors incorporate both socioeconomic characteristics and journey constraints. Increasing willingness to use the public bicycle system should focus on these seven key factors, as discussed below.

As shown previously with regard to the Ordered Logit and Probit model, $\beta_{k}$ represents the the weights of each independent variable and the importance of each to the dependent variable. Table 2 showed the coefficient magnitudes of these variables, and the significance is greatest to least as follows: gender (female), job1 (student), car 
ownership (not owning a private car), el (station facility level), ut (length of time of bicycle use), itap (load time at peak), and ra (rationality of public bicycle docking station location). Gender (female), job1 (student), and car ownership (not owning a private car) are socioeconomic factors, and the coefficient magnitudes of these variables were found to be the greatest in this research. The following journey restrictions were shown to be less important and to have relatively less impact on willingness to use the public bicycle system: station facility level (el), length of time of bicycle use (ut), load time at peak (itap), and rationality of public bicycle docking station location (ra). Therefore, socioeconomic factors have a more relevant impact on willingness to use the public bicycle system than journey restrictions. These results are discussed in more detail below.

As seen in Table 3, the sign is positive for the following partial effects: gender (female), car ownership (not owning a private car), job1 (student), and station facility level (el). This indicates that an improvement of 1 in the value scale of these variables causes an increase in the probability to score willingness to use the public bicycle system as "very willing." The variable with greatest impact on increased probability of getting the best evaluation ("very willing") of willingness is gender (female). The partial effects corresponding to this variable quantify an increase of $12.75 \%$ in the probability of scoring "very willing." The job1 (student) variable will have a $9.51 \%$ impact on the increased probability of users indicating "very willing." Similarly, an improvement of 1 in valuation scale of car ownership (not owning a private car) causes an increase of $7.05 \%$ in the probability of a score of "very willing." An improvement of 1 in the valuation scale of station facility level (el) causes an increase of $4.99 \%$ in the probability of a score of "very willing." These findings also indicate that female or students users will be more likely to choose the public bicycle system when all other conditions are the same. Additionally, users who have no private car will tend to use the public bicycle system more than those who have a private car. If the station facility level is better, then willingness is likely to be greater.

In contrast, an improvement of 1 in the valuation scale of the the following partial effects with a negative sign will result in decreases in the probability of a score of "very willing:" load time at peak time (itap) (5.55\% decrease), length of time of bicycle use (ut) (3.2\% decrease), and rationality of public bicycle docking location ( $\mathrm{ra}$ ) (7.32\% decrease). These results show that if itap and ut are increased, user willingness to use the public bicycle system ("very willing") may be reduced. If ra is less reasonable and more inconvenient, users will be less likely to be "very willing" to select the public bicycle for their commute, as they do not wish to spend more time using a bicycle and transferring to other transportation modes. Therefore, it is essential to reduce the load time at the peak time and the length of time using a public bicycle and to optimize the location of the public bicycle docking station to increase the usage rate of public bicycles.

\section{Conclusions and Recommendations}

Public bicycles play a vital role in sustainable transportation development. By adopting a discrete choice model (Ordered Logit and Probit model), this paper contributes to research on willingness to use a public bicycle system, including a study of the relative 
importance of influential variables on choice willingness. Specifically investigated were the effects on user choice willingness of an implemented public bicycle system in Nanjing.

First, this research identified seven factors that influence willingness to use Nanjing's public bicycle system: load time at peak time, length of time using bicycle, rationality of public bicycle docking station location, station facility level, gender, car ownership, and employment. Therefore, any strategy to increasing willingness to use the public bicycle system should consider these variables.

Second, this research included an analysis of the relevance of influential variables in willingness to use the public bicycle system. Socioeconomic factors were shown to have a more important impact on willingness than journey restricions. This finding indicates that subjectivity of the user is shown to be relatively strong for choosing the public bicycle.

Finally, according to the partial effects results, it was found that an improvement of 1 in the valuation scales for length of time of bicycle use (ut), load time at peak (itap), and rationality of public bicycle docking station location ( $\mathrm{ra}$ ) will cause a decrease in the probability of a user indicating that he is "very willing" to use the public bicycle system. Load time at peak is related to the number of bicycles in the public bicycle docking station. If a station does not have sufficient bicycles to provide to users, the users will not be able to borrow the bicycles at the peak and instead must wait for bicycles that could be redistributed from another station. This increases the load time at peak, which reduces the score to "very willing." Similarly, if the length of time using a public bicycle is increased, users being "very willing" may be reduced. This may be a direct result of the locations of public bicycle docking stations being less reasonable and more inconvenient for users.

Based on these findings, the following recommendations for public bicycle development are made. The government should (1) build reasonably-located public bicycle docking stations and (2) design more reasonable redistribution of public bicycles so that sufficient bicycles are provided for users, thereby reducing the loading time at peak. Both of these approaches could encourage more people (including private cars owners) to use the public bicycle system, and as a result, reduce the total number of vehicles on Nanjing's roads.

This research had some limitations. More stratifying socioeconomic variables (such as educational background, income level, etc.) were not taken into account; these data could be obtained through additional investigation in future studies. Further research also should compare the social, economic, and ecological effects of conversion to a public bicycle system with other transportation modes so people could choose to use public bicycles based on consideration of their social benefits, reduction in urban traffic congestion, and ability to solve the urban traffic "last mile" problem. 


\section{Acknowledgments}

This research was sponsored by the National Basic Research Program of China (973 Program) (No. 2012CB725402), research on key technologies of multimodal public transportation in China, and by the National Natural Science Foundation of China (No.61573098), research on the carrying capacity and scheduling models of urban flexroute transit systems.

\section{References}

Bachand-Marleau, J., B. H. Y. Lee, and A. M. El-Geneidy. 2012. “Better Understanding of Factors Influencing Likelihood of Using Shared Bicycle Systems and Frequency of Use." Transportation Research Record, 2314: 66-71.

Debrezion, G., E. Pels, and P. Rietveld. 2009. "Modelling the Joint Access Mode and Railway Station Choice." Transportation Research Part E: Logistics and Transportation Review, 45(1): 270-283.

dell'Olio, L., A. Ibeas, and P. Cecin. 2010. “Modeling User Perception of Bus Transit Quality." Transport Policy, 17(6): 388-397.

DeMaio, P. 2009. "Bike-sharing: History, Impacts, Models of Provision, and Future." Journal of Public Transportation, 12(4).

Givoni, M., and P. Rietveld. 2007. "The Access Journey to the Railway Station and Its Role in Passengers' Satisfaction with Rail Travel."Transport Policy, 14(5): 357-365.

Hensher, D. A., C. Mulley, and N. Yahya. 2009. "Passenger Experience with QualityEnhanced Bus Service Level Constraints: The Tyne and Wear 'Superoute' Service." Transportation, 37(2): 239-256.

Liu, M., L. Yu., and Z. Zhang. 2008. "Cumulative Logistic Regression Based Measurement Models Road Traffic Congestion Intensity." Journal of Beijing Jiaotong University, 32(6).

Mckelvey, R., and W. Zavoina. 1975. "A Statistical Model for the Analysis of Ordinal Level Dependent Variables." Journal of Mathematical Sociology, 4, 1975, 103-120.

Nanjing Institute of City and Transport Planning (NICTP). 2013. "Annual Report of Nanjing Transport." Nanjing: Nanjing Institute of City and Transport Planning.

National Bureau of Statistics of China. 2013. Statistic Yearbook of China. Available at http://www.stats.gov.cn.

Ortuzar, J. D., and L. G. Willumsen. 2011. Modeling Transport, $4^{\text {th }}$ edition. Hoboken, N.J.: John Wiley and Sons.

Rainer-Harbach, M., P. Papazek, B. Hu, et al. EvoCOP, LNCS 7823, 2013:121-132.

Raviv, T., M. Taur, and I. A. Forma. 2013. "Static Repositioning in a Bike-Sharing System: Models and Solution Approaches." European Journal of Transport Logistics., 2(3): 187-229. 
Shaheen, S., H. Zhang, E. Martin, and S. Guzman. 2010. "Bikesharing in Euope, the Americas, and Asia." Transportation Research Record, 2143: 159-167.

State Council. 2012. State Council's Guidance on the Priority Development of Urban Transit. Available at http://www.gov.cn/zwgk/2013-01/05/content_2304962.htm.

Wang, J., and Z. Guo. 2001. Logistic Regression Model-Methods and Application. Beijing: Higher Education Press: 237-239.

\section{About the Authors}

PeiYu Feng (fpy_131@sina.com) is with the School of Transportation at Southeast University, China.

WENQUAN LI (wenqli@seu.edu.cn) is a Professor at the School of Transportation at Southeast University. He holds a Ph.D. from the School of Transportation at Southwest Jiaotong University, and his research interests include transportation planning and management, traffic flow theory, traffic safety, and public transit. 